\title{
Tumor control and trigeminal dysfunction improvement after stereotactic radiosurgery for trigeminal schwannomas: a systematic review and meta-analysis
}

\author{
Iulia Peciu-Florianu ${ }^{1}$ • Jean Régis ${ }^{2}$ - Marc Levivier ${ }^{3,4}$ Michaela Dedeciusova $^{5,6}$ - Nicolas Reyns $^{1}$. \\ Constantin Tuleasca ${ }^{1,3,4,7}$
}

Received: 13 May 2020 / Revised: 31 October 2020 / Accepted: 3 November 2020 / Published online: 13 November 2020

(C) The Author(s) 2020

\begin{abstract}
Trigeminal nerve schwannomas (TS) are uncommon intracranial tumors, frequently presenting with debilitating trigeminal and/ or oculomotor nerve dysfunction. While surgical resection has been described, its morbidity and mortality rates are non-negligible. Stereotactic radiosurgery (SRS) has emerged with variable results as a valuable alternative. Here, we aimed at reviewing the medical literature on TS treated with SRS so as to investigate rates of tumor control and symptomatic improvement. We reviewed manuscripts published between January 1990 and December 2019 on PubMed. Tumor control and symptomatic improvement rates were evaluated with separate meta-analyses. This meta-analysis included 18 studies comprising a total of 564 patients. Among them, only one reported the outcomes of linear accelerators (Linac), while the others of GK. Tumor control rates after SRS were 92.3\% (range 90.1-94.5; $p<0.001$ ), and tumor decrease rates were 62.7\% (range 54.3-71, $p<0.001$ ). Tumor progression rates were $9.4 \%$ (range 6.8-11.9, $p<0.001$ ). Clinical improvement rates of trigeminal neuralgia were 63.5\% $(52.9-74.1, p<0.001)$ and of oculomotor nerves were $48.2 \%$ (range 36-60.5, $p<0.001$ ). Clinical worsening rate was $10.7 \%$ (range 7.6-13.8, $p<0.001$ ). Stereotactic radiosurgery for TS is associated with high tumor control rates and favorable clinical outcomes, especially for trigeminal neuralgia and oculomotor nerves. However, patients should be correctly advised about the risk of tumor progression and potential clinical worsening. Future clinical studies should focus on standard reporting of clinical outcomes.
\end{abstract}

Keywords Trigeminal schwannoma $\cdot$ Radiosurgery $\cdot$ Gamma Knife $\cdot$ Trigeminal neuralgia

\section{Introduction}

Trigeminal nerve schwannomas (TS) are rare, representing less than $1 \%$ of all intracranial tumors $[39,50]$ and 0.8 to $8 \%$ of intracranial nerve sheath tumors $[10,38]$. They develop

Dr Peciu-Florianu and Régis equally contributed as a first author.

Dr Reyns and Tuleasca equally contributed as a senior author.

Constantin Tuleasca

constantin.tuleasca@chuv.ch; constantin.tuleasca@gmail.com

1 Neurosurgery and Neurooncology Service, Centre Hospitalier Regional Universitaire de Lille, Roger Salengro Hospital, Lille, France

2 Stereotactic and Functional Neurosurgery Service and Gamma Knife Unit, CHU Timone, Marseille, France

3 Department of Clinical Neurosciences, Neurosurgery Service and Gamma Knife Center, Lausanne University Hospital (CHUV), Lausanne, Switzerland from the sheaths of the trigeminal root, ganglion, or nerves. They usually appear at the level of Meckel's cave, posterior fossa, or cavernous sinus and usually overlap multiple cranial fossae. Clinically, patients usually present with trigeminal nerve dysfunction, the most common symptom being
$4 \quad$ Faculty of Biology and Medicine and Centre Hospitalier Universitaire Vaudois (CHUV), Department of Clinical Neurosciences, Neurosurgery Service and Gamma Knife Center, University of Lausanne, Lausanne, Switzerland

5 First Faculty of Medicine, Charles University in Prague, Prague, Czech Republic

6 Department of Neurosurgery and Neurooncology, Military University Hospital Prague, Prague, Czech Republic

7 Signal Processing Laboratory (LTS 5), Ecole Polytechnique Fédérale de Lausanne (EPFL), Lausanne, Switzerland 
trigeminal neuralgia (TN) [52]. Other common symptoms are numbness or burning sensation along the distribution of the nerve or one of its branches. Long-standing TS may also present with motor symptoms, such as masticatory disturbance and deviation of the jaw, but also symptoms of oculomotor nerves compression $[38,39]$.

Complete microsurgical resection remains challenging, due to their close relationship to vascular structures in the cavernous sinus, Meckel's cave, and the skull base while extending from the middle towards the posterior fossa and vice versa [38]. Consequently, radical resection can be associated with further morbidity and mortality [39].

Stereotactic radiosurgery (SRS) is considered a valuable therapeutic alternative for treating benign intracranial tumors, due to its minimal invasiveness as well as to its safety profile and efficacy on vestibular [14, 24, 34, 44, 45] and nonvestibular schwannomas $[7,29]$. Twenty years ago, a first report by Huang et al. [16] evaluated the role of SRS by Gamma Knife (GK) in trigeminal nerve schwannomas. Since then, many institutions reported their results in treating this uncommon pathology $[12-14,19,32,40,42,50]$. Biological behavior of different benign Schwann cell tumors is often considered similar, thus making SRS a valuable treatment option.

Here, we performed a systematic review and meta-analysis of the published series on SRS for TS. We were particularly interested in evaluating tumor control, as well as symptom improvement for patients with secondary trigeminal neuralgia (TN) [5]. The available case series show a significant variability in both tumor control and clinical results. Understanding how SRS impacts the symptomatic course of secondary TN patients is critical, allowing better patient selection. Moreover, this could potentially suggest a standardized method for outcome reporting. In this paper, we provide the first systematic review and meta-analysis of outcomes following SRS for TS, researching improvement of pretherapeutic secondary TN or diplopia after SRS in TS; there is no comparison to other therapeutic approach.

\section{Material and methods}

\section{Article selection and data extraction}

A PubMed search was performed for entries between January 1990 and December 2019 using the following query
Fig. 1 PRISMA flow-chart with study selection details
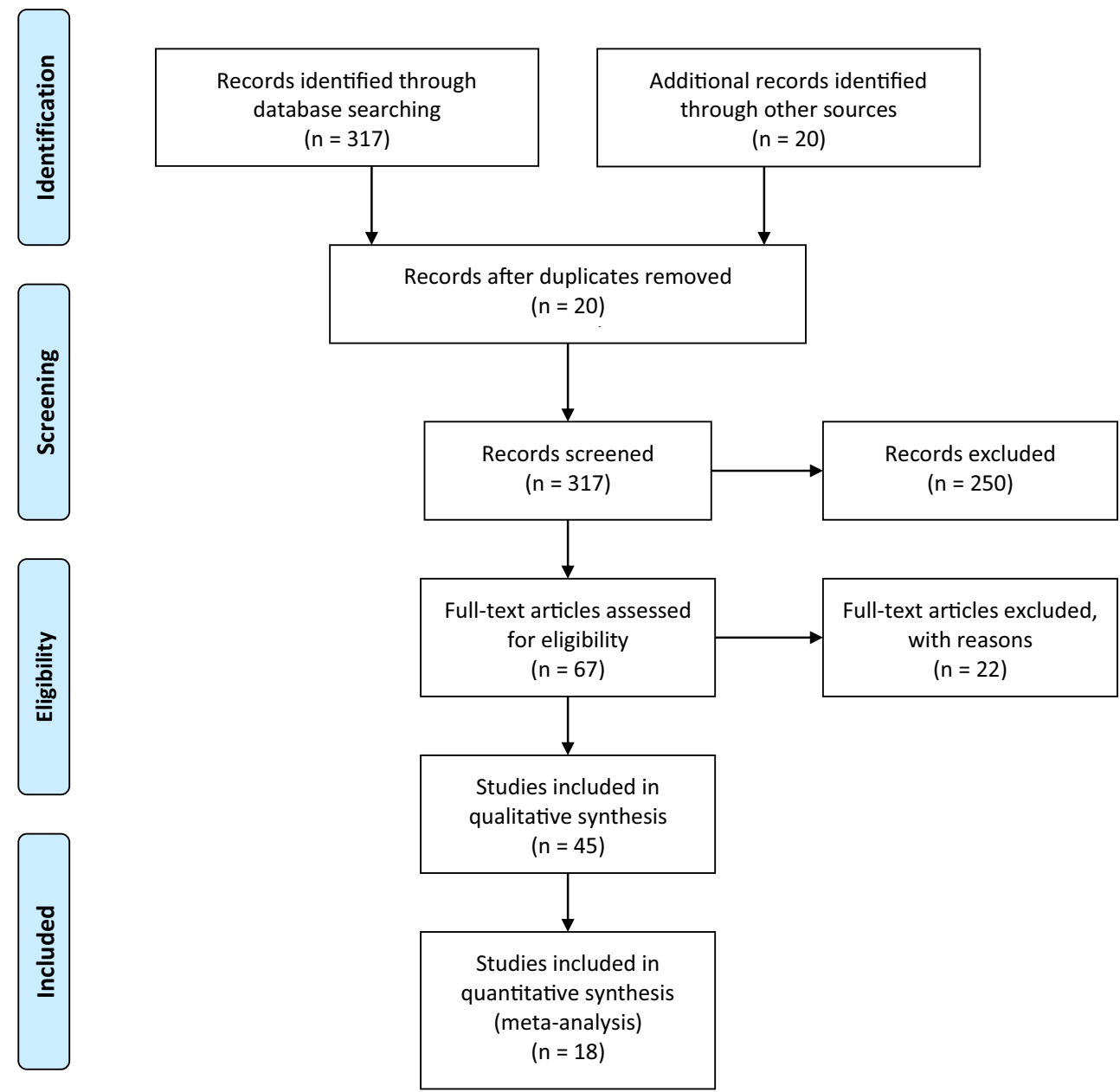


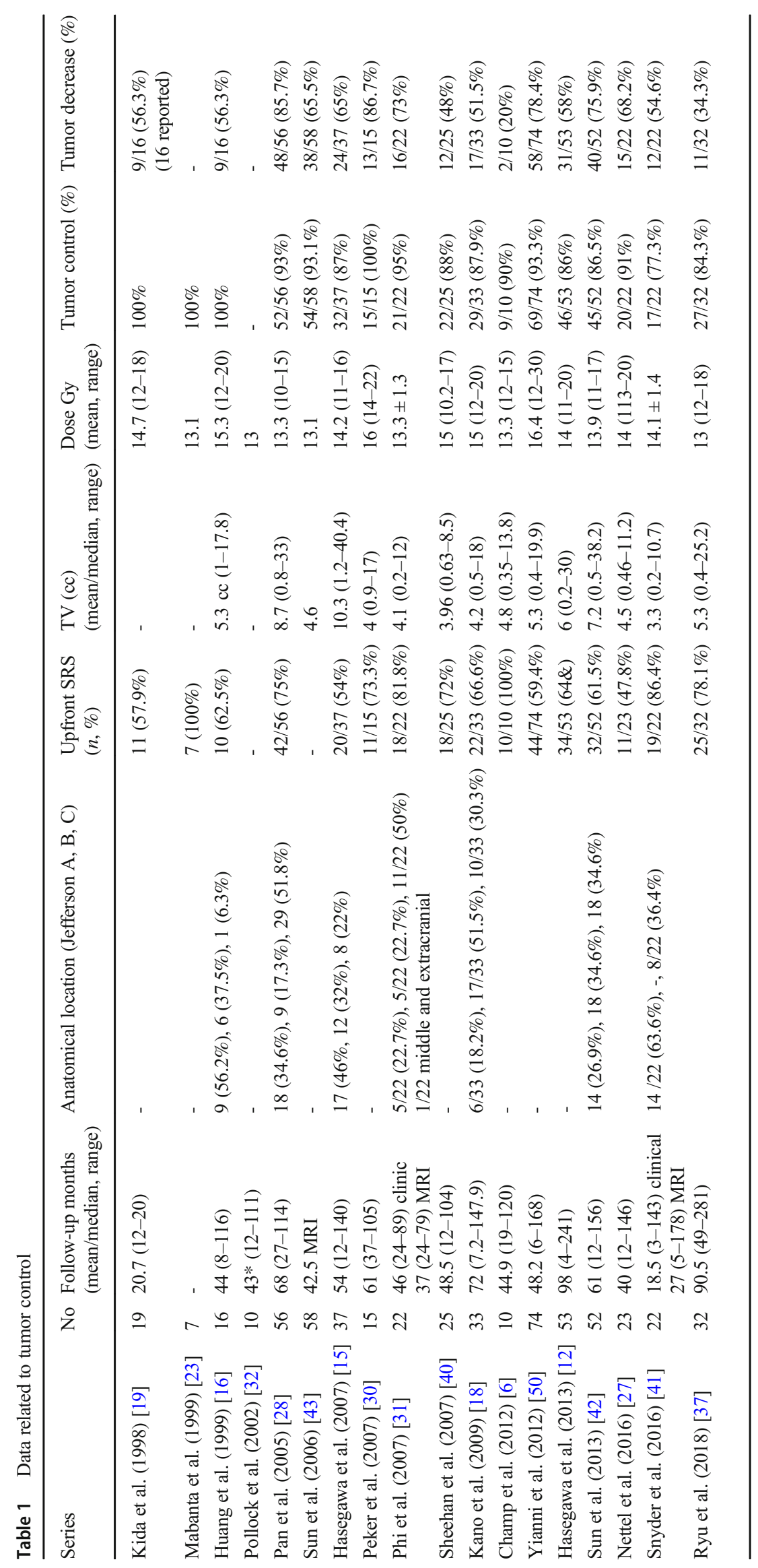




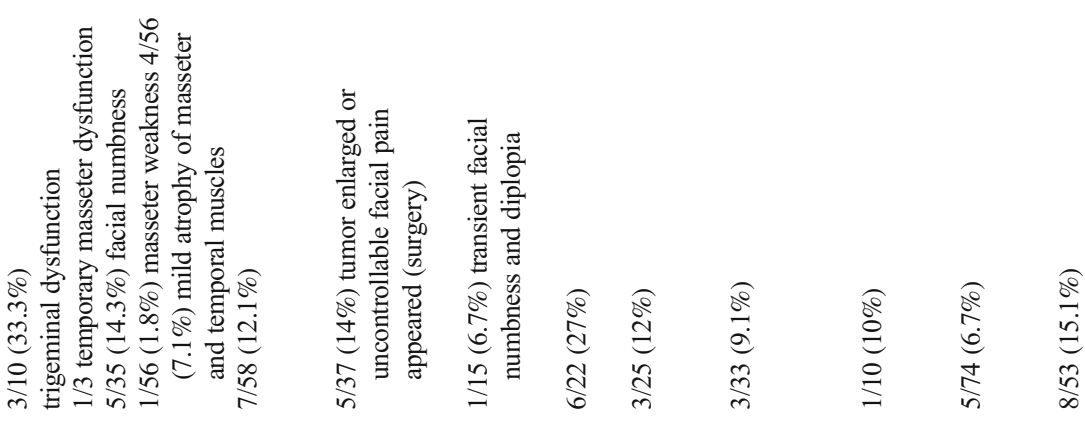

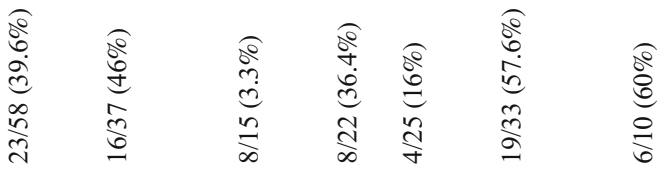

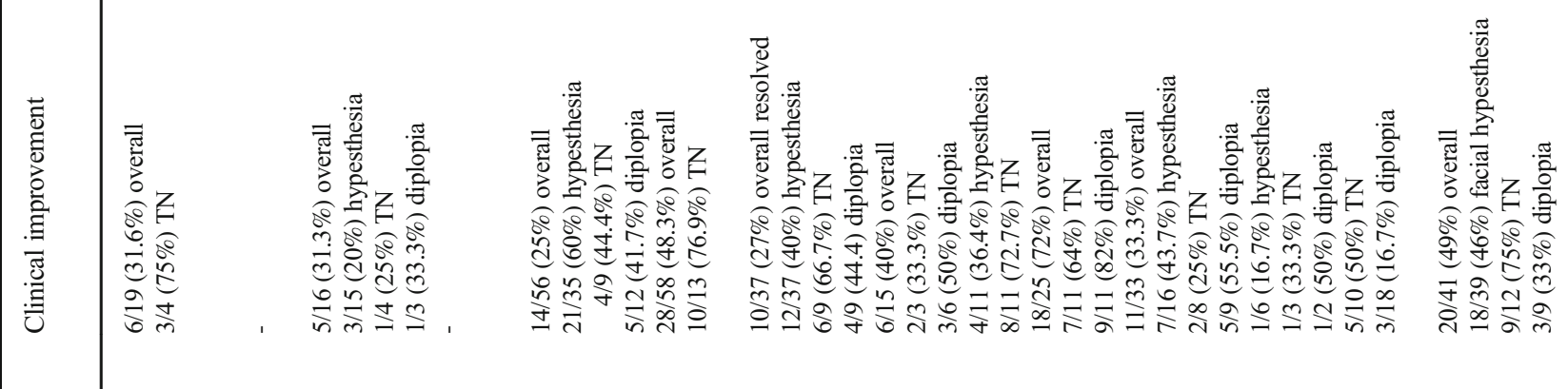
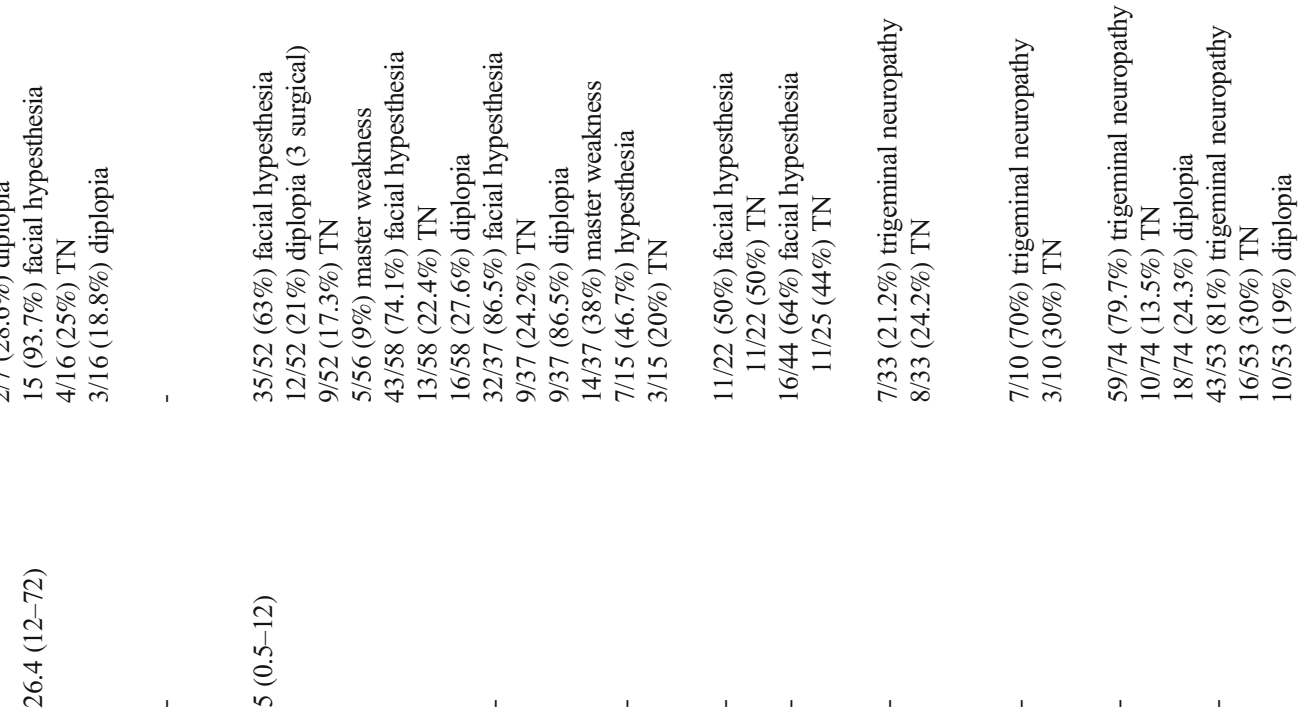

$\therefore \quad$ in

in n n

$\because \frac{1}{2}$

$\therefore \quad$ ก

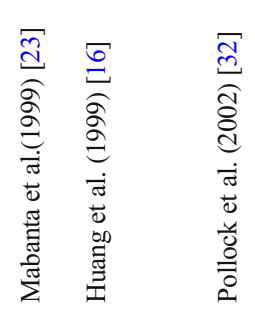

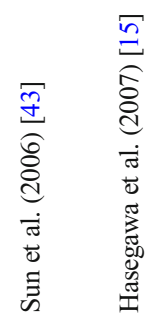

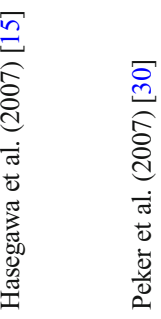

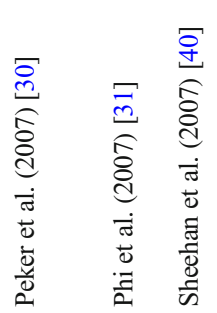

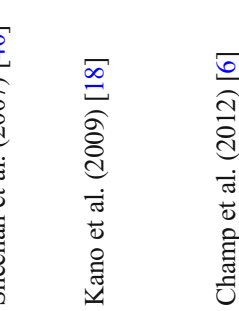

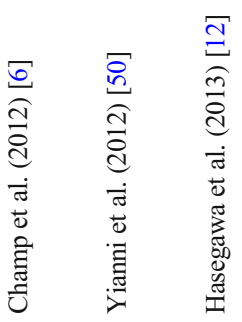


guidelines of January 1990 to December 2019: ((trigeminal AND (radiosurgery OR Gamma Knife)) AND (schwannoma)). We selected the 1990 as a starting date because prior to this date, there were few papers published in common indications on SRS, whereas TS was an uncommon one. Inclusion criteria required that each article be a peerreviewed clinical study or case series of TS treated with SRS, independently of the device. As such, case reports, non-English studies, and conference papers or abstracts were excluded. Other exclusion criteria identified studies reporting non-vestibular schwannomas or TS treated with other radiation means than SRS (including radiotherapy). The article selection is illustrated in Fig. 1, which includes the studies reported subsequently in Tables 1 and 2. Two separate reviewers applied the inclusion criteria to the PubMed search result; there were no disagreements. Moreover, four separate reviewers applied the exclusion criteria to the remaining articles.

This study was performed in accordance with the published Preferred Reporting Items for Systematic Reviews and MetaAnalyses (PRISMA) guidelines [26].

In extracting data from these studies, we paid attention to the diagnosis modality and clinical and neuroimaging classifications. In most series, neuroimaging diagnosis in patients without previous surgery was based upon classical characteristics of extra-axial uniformly enhancing tumors, involving the middle and/or posterior fossa, without any evidence of dural tail, accompanied by predominant clinical signs of trigeminal nerve dysfunction [35]. Clinical assessment was not reported using particular scales, especially in the context of TN. Jefferson's classification scheme was used for neuroimaging extensions: A, predominantly middle fossa; $\mathrm{B}$, posterior fossa; and $\mathrm{C}$, dumbbellshaped lesion involving both the middle and posterior fossa [17]; based upon the relationship with the brainstem, the classifications were types I (no compression of the brainstem), II (brainstem compression without deviation of fourth ventricle), and III (deviation of fourth ventricle).

We extracted data related to trigeminal dysfunction, TN, diplopia, tumor control, regression, stability, and progression before and after SRS.

\section{Statistical analysis using OpenMeta (Analyst) and random-effects model}

Due to the high variation in study characteristics, a statistical analysis using a binary random-effects model (DerSimonianLaird method) was performed. We used OpenMeta (Analyst) from the Agency for Healthcare Research and Quality.

Weighted summary rates were determined using metaanalytical models. Testing for heterogeneity was performed for each meta-analysis. 


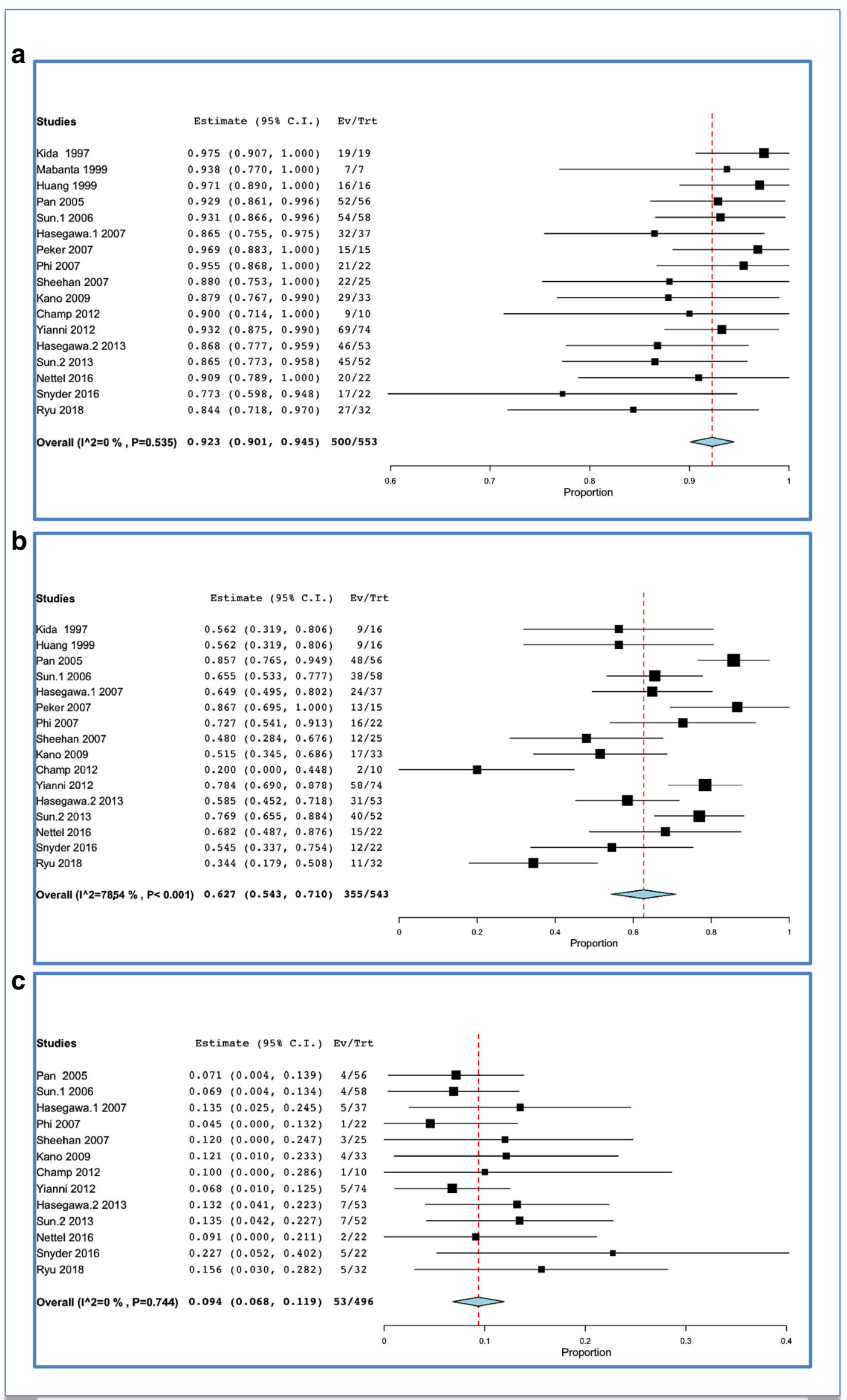


Fig. 2 Tumor control rates after SRS for TS: a tumor control (including stability and decrease in volume); $\mathbf{b}$ tumor decrease; $\mathbf{c}$ tumor progression rates

Pooled estimates using meta-analytical techniques were obtained for all the outcomes previously described in the same section.

\section{Results}

\section{Study selection}

This meta-analysis included 18 studies, comprising a total of 564 patients $[6,12,15,16,18,19,23,27$, 28, 30-32, 40-43, 50]. Among those, only one reported the outcomes of linear accelerators (Linac) [23] while the others of GK.

\section{Study characteristics}

The detailed study characteristics can be seen in Tables 1 and 2.

\section{Tumor control after SRS}

Tumor stability or regression after SRS was described in 500 out of 553 of the reported patients, which corresponds to a rate of $92.3 \%$ (range 90.1-94.5; $\mathrm{I}^{\wedge} 2=0 ; p$ heterogeneity $=0.53$; $p<0.001$; Fig. 2a). Factors involved in better tumor control were as follows: anatomical location (for Jefferson types A, B, and $\mathrm{C}$ were 93,75 , and $86 \%$ at 5 years; for I, II, and III were 100,87 , and $50 \%$, respectively) [15]; root or ganglion tumor type [18]; female sex or $<8$ cc tumor volume [18]; marginal and maximal dose [12]; and target volumes of less than 5 cc [37]. Tumor expansion was associated with higher prescribed doses (mean 14.9 versus $13.6 \mathrm{~Gy}$ ) and with further lack of tumor control [41]. Transient tumor expansion was also associated with cystic components [37].

\section{Tumor decrease after SRS}

Tumor decrease or regression was encountered in 355 out of the 543 reported patients, which corresponded to a rate of $62.7 \%$ (range 54.3-71; $\mathrm{I}^{\wedge} 2=78.5 ; p$ heterogeneity and $p<0.001$; Fig. 2b).

\section{Tumor progression after SRS}

Tumor progression was encountered in 53 out of the 496 cases, which corresponded to a rate of $9.4 \%$ (range $6.8-$ 11.9; $\mathrm{I}^{\wedge} 2=0 \% ; p$ heterogeneity $=0.74 ; p<0.001 ;$ Fig. $2 \mathrm{c}$ ).

\section{Overall clinical improvement}

Overall clinical improvement was encountered in 185 out of 423 patients, which corresponded to a rate of $43.2 \%$ (34.352.2; $\mathrm{I}^{\wedge} 2=73.31 \% ; p$ heterogeneity and $p<0.001$; Fig. 3a).

\section{Overall clinical stabilization}

Clinical stabilization was encountered in 137 out of 332 patients, which corresponded to a rate of $42.7 \%$ (33.8-51.5; $\mathrm{I}^{\wedge} 2=64.72 \% ; p$ heterogeneity $=0.001, p<0.001$; Fig. $\left.3 \mathrm{~b}\right)$.

\section{Overall clinical worsening}

Clinical worsening (Fig. 3a) was reported in 63 out of 509 cases, which corresponded to a rate of $10.7 \%$ (7.6-13.8; $\mathrm{I}^{\wedge} 2=23.35 \% ; p$ heterogeneity $=0.195$ and $p<0.001$; Fig. 3c). Cranial neuropathies have been considered in some studies as associated with loss of central enhancement, tumor expansion, and tumor location extended in the cavernous sinus [31]. Symptom worsening was classically associated with transient tumor expansion [31].

\section{Clinical improvement of TN}

Clinical improvement of trigeminal neuralgia was encountered in 80 out of 126 patients, which corresponded to a rate of $63.5 \%\left(52.9-74.1 ; \mathrm{I}^{\wedge} 2=45.65 \%\right.$; $p$ heterogeneity $=0.028$, $p<0.001$; Fig. 4a).

\section{Clinical improvement of facial hypoesthesia}

Clinical improvement of facial hypoesthesia was reported in 103 out of 252 cases, which corresponded to a rate of $39.1 \%$ $\left(31.4-46.8 ; \mathrm{I}^{\wedge} 2=37.45 \% ; p\right.$ heterogeneity $=0.109$ and $p<0.001$; Fig. 4b).

\section{Clinical improvement of diplopia}

Clinical improvement of diplopia was reported in 36 out of 76 cases, which corresponded to a rate of $48.2 \%\left(36-60.5 ; \mathrm{I}^{\wedge} 2=\right.$ $22.8 \%$; $p$ heterogeneity $=0.233$ and $p<0.001$; Fig. $4 c$ ).

\section{Adverse reactions}

Most commonly reported adverse reactions were pseudoprogression (variable as reported by series and based upon neuroimaging), ranging from $2.2 \%$ [30] to $37.5 \%$ [16]; cranial nerve V dysfunction (30\%) [32]; expansion/enlarged cyst $(11 \%)$ or increased pain $(10 \%)$ [12]; cranial nerve dysfunction (8.6\%) [27]; pseudocapsule formation [40]; and hydrocephalus (3.1\%) [37] as reported individually in each of the series. 


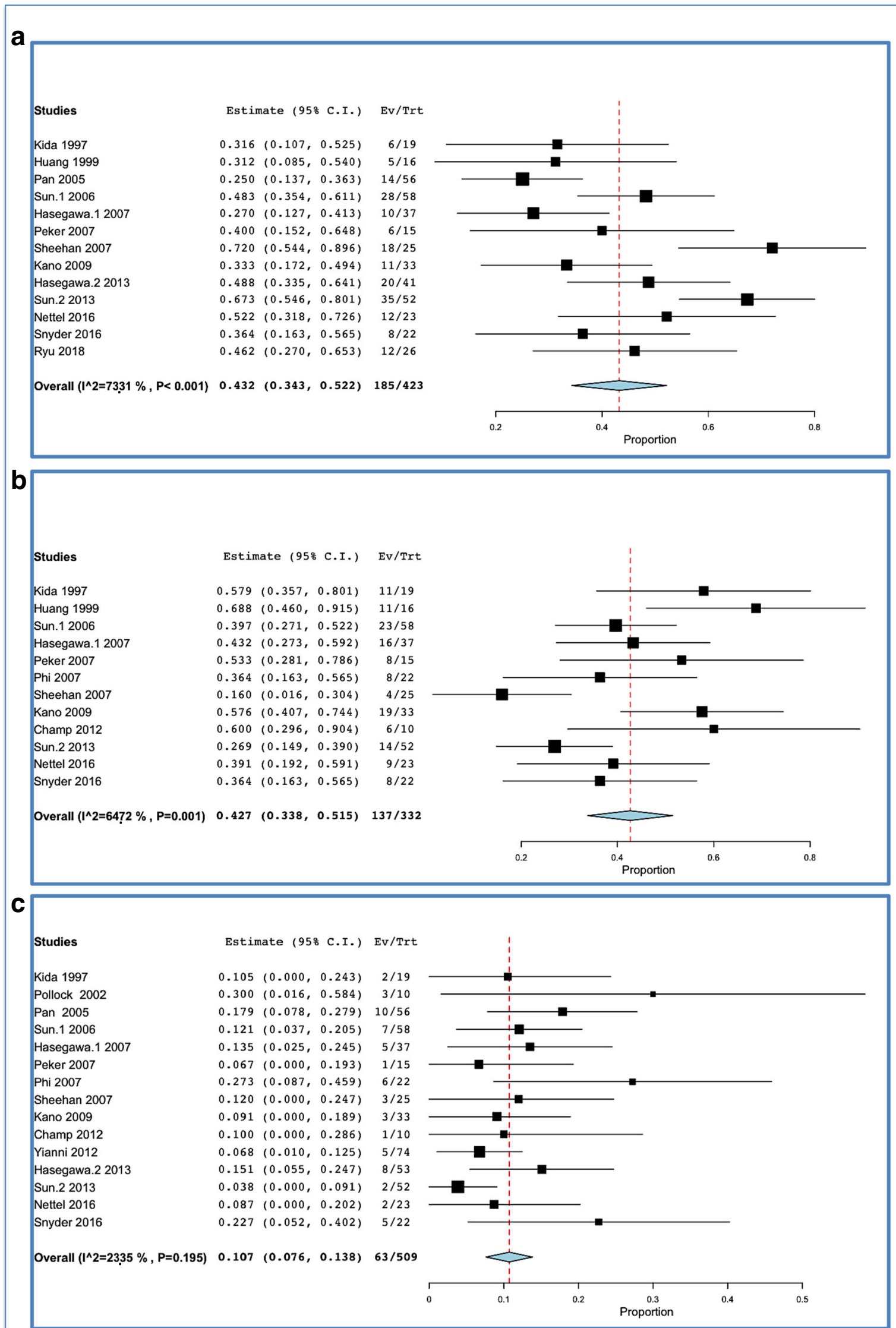


Fig. 3 Clinical course after SRS for TS: a overall improvement; b stabilization; $\mathbf{c}$ worsening

\section{Discussion}

In this study, we provide a meta-analysis and systematic review of tumor control and symptomatic improvement after SRS for TS. This meta-analysis included 18 studies comprising a total of 564 patients. Tumor control rates after SRS were as high as $92.3 \%$ and tumor decrease rates $62.7 \%$, while tumor progression rates $9.4 \%$. Clinical improvement rates of trigeminal neuralgia were $63.5 \%$, and oculomotor nerves improvement rates were $48.2 \%$.

Historical standard treatment for TS was microsurgical resection. As many other benign skull-base pathologies, TS have been once considered forbidding tumors for microsurgical resection due to high rates of morbidity and mortality. Nowadays, radical resection is considered feasible, using a combination of skull-base approaches and microsurgery. However, neuropathies following surgery vary between 6.6 and $86 \%[1,3,25,38]$. The major challenges related to complete microsurgical resection are injury of cavernous sinus components (including carotid artery or the abducens nerve) and management of brainstem adherence of tumor capsule, in cases with posterior fossa extension [9, 38, 39]. The largest surgical series was published by Konovalov et al. [22], who reported 111 cases. The authors achieved radical removal in 86 patients $(77.5 \%)$, with symptomatic recurrence in 13 $(11.7 \%)$ cases. Fukushima described a series of 38 patients, with radical removal in $30(78.9 \%)$ out of 38 cases, without any perioperative death [9]. Samii et al. reported the total removal in $10(83.3 \%)$ of 12 patients [38]. Both cases with subtotal resection developed tumor progression. Postoperative complications included tetraparesis or facial nerve palsy. Al-Meftyet al. [1] reported a surgical series of 25 cases, all involving the cavernous sinus. Preoperative trigeminal nerve sensory deficit improved in $44 \%$ of cases and facial pain decreased in $73 \%$. Three cases had tumor recurrence, with one experiencing another 2 surgeries [1]. Three patients developed cranial nerve neuropathies. Further skull-base approaches have been developed, providing better tumor exposure with minimal brain retraction without increased risk of morbidity. Recent study series by Goel et al. [11] reported a total resection rate in $73 \%$ of cases. Mortality rates have progressively declined from as high as $41 \%$ before 1956 to $25 \%$ before 1970 and further decreasing to $5.3 \%[3,39]$ or even to $2.7 \%$ in more recent series [11]. Radical resection remains challenging, even in experienced hands, despite the most recent advances in skull-base surgery and neuromonitoring. Progression rates after subtotal resection, without adjuvant treatments, range from 12 to $35.7 \%[1,3,25,38]$.
The current literature contains few series reporting the role of fractionated radiotherapy (FRT) in this pathology. Wallner et al. [47] reported 8 cases, with a tumor control rate of $50 \%$. The administrated dose was $45-54 \mathrm{~Gy}$, with 1.6 to $1.8 \mathrm{~Gy} /$ fraction. Another series by Zabel et al. [51] reported 13 patients, treated with $57.6 \mathrm{~Gy}$, with $100 \%$ tumor control, with one mild worsening of preexisting trigemina hypesthesia.

A unique comparison between SRS and FRT [6] revealed higher toxicity in the FRT group (38.5 versus $0 \%$ ), although lesions treated with FRT had higher volumes (mean 9.5 versus $4.8 \mathrm{cc}$ ).

Currently and during the past 20 years, SRS has been primarily used as a primary or second line treatment [16]. The mechanism of action of SRS in schwannomas has been considered a combination between direct tumoricidal effects and delayed intratumoral vascular obliteration, as reported by in vitro experiments [2]. For example, in vestibular schwannomas, the used radiation doses were initially higher, followed subsequently by dose escalation, with similar tumor control rates and better clinical outcomes [20]. Large tumors can be treated using subtotal or gross total resection followed by GKR, as previously published in non-vestibular [8, 29, 49] and vestibular schwannomas $[8,46]$. Other approaches might include staged volume radiosurgery, in selected cases [7]. Challenging aspects might be related to the proximity with the optic apparatus. It was initially considered that a maximal delivered dose less than 8 Gy should be kept; however, recent trials suggested that this dose could be safely increased [33]. Cystic benign tumors have been initially considered less responsive to SRS. Nevertheless, this myth has been recently invalidated [4]. In case of tumor progression, further SRS versus microsurgical resection, depending on the volume, remain viable options. Hydrocephalus can be managed with ventriculo-peritoneal shunt. The question concerning trigeminal dysfunction after GKR for TS remains open, especially as the doses used here are much lower as compared to those used in idiopathic TN [21]. The risk of malignancy after SRS is currently considered low in all available long-term follow-up [48].

Lastly, one must take into account that SRS and particularly GKR have had an important technique refinement. In fact, some of the patients reported here have been treated with crude dosimetric algorithm, including KULA (Elekta Instruments, AB, Sweden). In this respect, the clinical and radiological results have significantly improved and they will keep on improving.

\section{Limitations}

There are several limitations to consider in our investigation. The first one is related to the innate shortcomings of metaanalysis techniques in neurosurgical studies. The second one refers to the fact that data were aggregated from multiple trials 
a

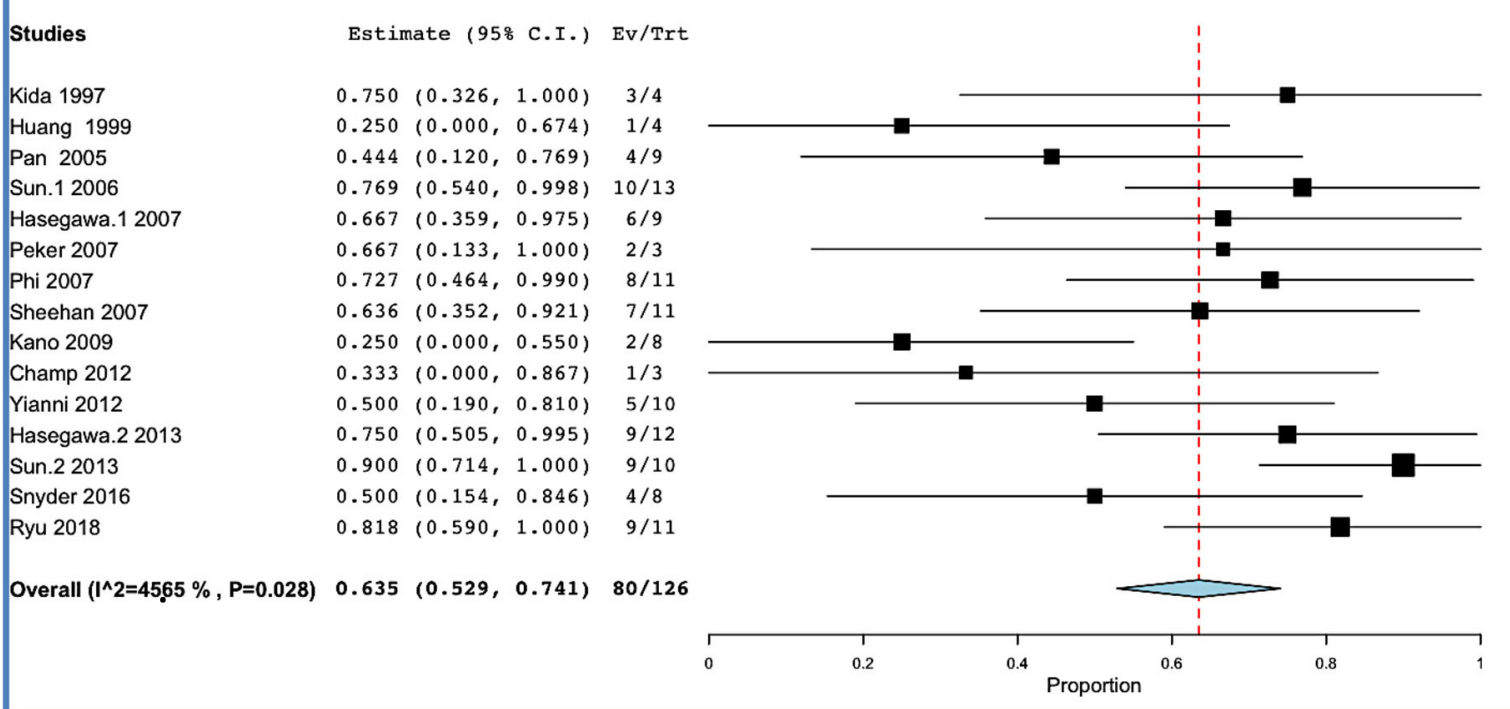

b

Studies

Estimate (95\% C.I.) Ev/Trt

Huang 1999

Pan 2005

Hasegawa.1 2007

$0.200(0.000,0.402)$

$0.600(0.438,0.762)$

$0.324(0.173,0.475)$

$0.364(0.079,0.648)$

$0.438(0.194,0.681)$

Phi 2007

$0.167(0.000,0.465)$

$0.462(0.305,0.618)$

Champ 2012

Hasegawa.2 2013

Sun 2013

$0.385(0.252,0.517)$

$0.333(0.095,0.572)$

$0.462(0.270,0.653)$

Ryu 2018

Overall ( $\left(\left.\right|^{\wedge} 2=37.45 \%, P=0.109\right) \quad 0.391 \quad(0.314,0.468) \quad 103 / 252$

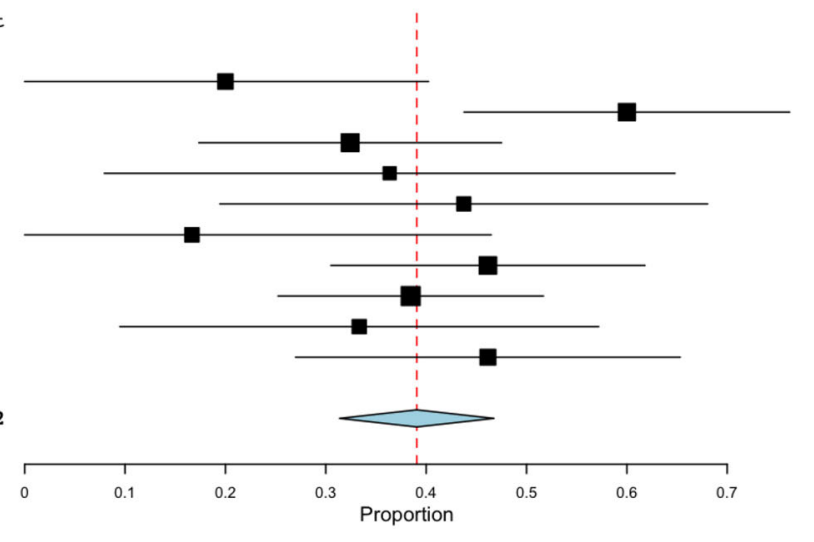

$3 / 15$
$21 / 35$

$12 / 37$

$4 / 11$

$18 / 39$

$20 / 52$

$5 / 15$

C

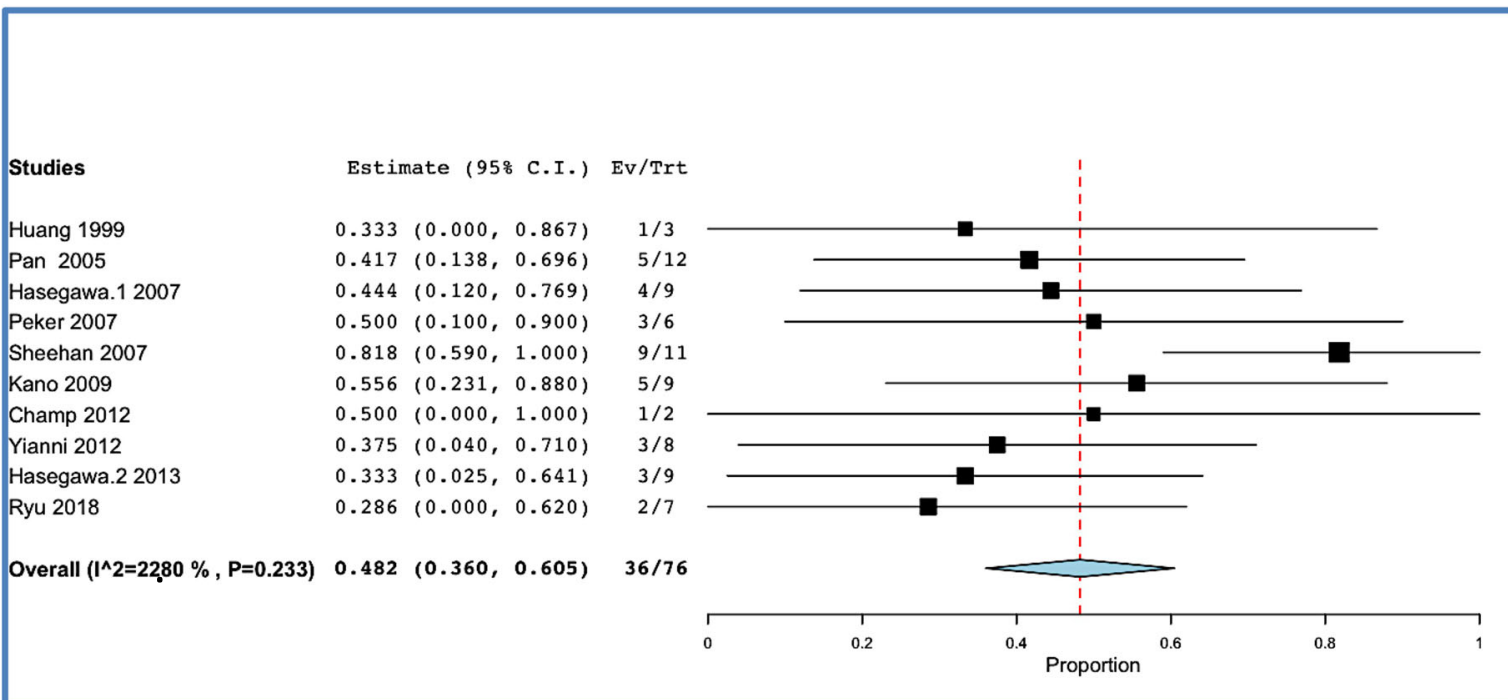


Fig. 4 Specific outcomes after SRS: a trigeminal neuralgia; b trigeminal hypesthesia; c oculomotor

to generate a larger patient study group. While this type of approach enhances detection of statistically significant correlations between different parameters, the validity of the final data depends on the data quality collected by other authors and might be susceptible to selection bias. The third limitation is the number of patients which has been reported for some of the outcomes, with several studies lacking to report all data. The fourth limitation is the lack of scale reporting, in particular for trigeminal neuralgia, such as the Barrow Neurological Institute scale [36].

\section{Conclusion}

Stereotactic radiosurgery is safe and effective for TS. Tumor control rates are as high as $92.3 \%$ and tumor decrease rates are $62.7 \%$, while tumor progression rates are $9.4 \%$. Clinical improvement rates of trigeminal neuralgia are $63.5 \%$, and oculomotor nerves improvement rates are $48.2 \%$. Future studies should report complete clinical evaluations, before and after SRS, using standardized scales.

Acknowledgments Lille and Lausanne University Hospital (CHUV) and University of Lausanne (UNIL), Faculty of Biology and Medicine (FBM).

Authors' contributions Study supervision: Tuleasca and Reyns; conception and design: Tuleasca, Reyns, and Peciu; statistical analysis: Tuleasca; first draft of the manuscript: Peciu and Tuleasca; critical revision of the first draft: Régis and Reyns; revised submitted version: all authors; approval of submitted version: all authors.

Funding Open access funding provided by University of Lausanne. Constantin Tuleasca gratefully acknowledges receipt of a "Young Researcher in Clinical Research Grant" (Jeune Chercheur en Recherche Clinique) from the University of Lausanne (UNIL), Faculty of Biology and Medicine (FBM), and Lausanne University Hospital (CHUV).

\section{Compliance with ethical standards}

Conflict of interest The authors declare that they have no conflict of interest.

\section{Ethics approval Not applicable.}

Open Access This article is licensed under a Creative Commons Attribution 4.0 International License, which permits use, sharing, adaptation, distribution and reproduction in any medium or format, as long as you give appropriate credit to the original author(s) and the source, provide a link to the Creative Commons licence, and indicate if changes were made. The images or other third party material in this article are included in the article's Creative Commons licence, unless indicated otherwise in a credit line to the material. If material is not included in the article's Creative Commons licence and your intended use is not permitted by statutory regulation or exceeds the permitted use, you will need to obtain permission directly from the copyright holder. To view a copy of this licence, visit http://creativecommons.org/licenses/by/4.0/.

\section{References}

1. Al-Mefty O, Ayoubi S, Gaber E (2002) Trigeminal schwannomas: removal of dumbbell-shaped tumors through the expanded Meckel cave and outcomes of cranial nerve function. J Neurosurg 96:453463. https://doi.org/10.3171/jns.2002.96.3.0453

2. Anniko M, Arndt J, Noren G (1981) The human acoustic neurinoma in organ culture. II. Tissue changes after gamma irradiation. Acta Otolaryngol 91:223-235. https://doi.org/10.3109/ 00016488109138503

3. Arseni C, Dumitrescu L, Constantinescu A (1975) Neurinomas of the trigeminal nerve. Surg Neurol 4:497-503

4. Bowden G, Cavaleri J, Monaco E III, Niranjan A, Flickinger J, Lunsford LD (2017) Cystic vestibular schwannomas respond best to radiosurgery. Neurosurgery 81:490-497. https://doi.org/10. 1093/neuros/nyx027

5. Burchiel KJ (2003) A new classification for facial pain. Neurosurgery 53:1164-1166; discussion 1166-1167. https://doi. org/10.1227/01.neu.0000088806.11659.d8

6. Champ CE, Mishra MV, Shi W, Siglin J, Werner-Wasik M, Andrews DW, Evans JJ (2012) Stereotactic radiotherapy for trigeminal schwannomas. Neurosurgery 71:270-277; discussion 277. https://doi.org/10.1227/NEU.0b013e318256bbc5

7. Comps JN, Tuleasca C, Goncalves-Matoso B, Schiappacasse L, Marguet M, Levivier M (2018) Upfront Gamma Knife surgery for facial nerve schwannomas: retrospective case series analysis and systematic review. Acta Neurochir 160:987-996. https://doi. org/10.1007/s00701-018-3503-2

8. Daniel RT, Tuleasca C, George M, Pralong E, Schiappacasse L, Zeverino M, Maire R, Levivier M (2017) Preserving normal facial nerve function and improving hearing outcome in large vestibular schwannomas with a combined approach: planned subtotal resection followed by gamma knife radiosurgery. Acta Neurochir 159: 1197-1211. https://doi.org/10.1007/s00701-017-3194-0

9. Day JD, Fukushima T (1998) The surgical management of trigeminal neuromas. Neurosurgery 42:233-240; discussion 240-231. https://doi.org/10.1097/00006123-199802000-00015

10. de Benedittis G, Bernasconi V, Ettorre G (1977) Tumours of the fifth cranial nerve. Acta Neurochir (Wien) 38:37-64. https://doi. org/10.1007/bf01401542

11. Goel A, Muzumdar D, Raman C (2003) Trigeminal neuroma: analysis of surgical experience with 73 cases. Neurosurgery 52:783790; discussion 790. https://doi.org/10.1227/01.neu.0000053365. 05795.03

12. Hasegawa T, Kato T, Iizuka H, Kida Y (2013) Long-term results for trigeminal schwannomas treated with gamma knife surgery. Int $\mathrm{J}$ Radiat Oncol Biol Phys 87:1115-1121. https://doi.org/10.1016/j. ijrobp.2013.09.010

13. Hasegawa T, Kato T, Yamamoto T, Naito T, Kato N, Torii J, Ishii K (2018) Long-term hearing outcomes after gamma knife surgery in patients with vestibular schwannoma with hearing preservation: evaluation in 92 patients with serial audiograms. J Neurooncol 138:283-290. https://doi.org/10.1007/s11060-018-2784-x

14. Hasegawa T, Kida Y, Kobayashi T, Yoshimoto M, Mori Y, Yoshida J (2005) Long-term outcomes in patients with vestibular schwannomas treated using gamma knife surgery: 10-year follow up. J Neurosurg 102:10-16. https://doi.org/10.3171/jns.2005.102. 1.0010 
15. Hasegawa T, Kida Y, Yoshimoto M, Koike J (2007) Trigeminal schwannomas: results of gamma knife surgery in 37 cases. J Neurosurg 106:18-23. https://doi.org/10.3171/jns.2007.106.1.18

16. Huang CF, Kondziolka D, Flickinger JC, Lunsford LD (1999) Stereotactic radiosurgery for trigeminal schwannomas. Neurosurgery 45:11-16; discussion 16. https://doi.org/10.1097/ 00006123-199907000-00002

17. Jefferson G (1953) The trigeminal neurinomas with some remarks on malignant invasion of the gasserian ganglion. Clin Neurosurg 1: 11-54. https://doi.org/10.1093/neurosurgery/1.cn_suppl_1.11

18. Kano H, Niranjan A, Kondziolka D, Flickinger JC, Dade Lunsford L (2009) Stereotactic radiosurgery for trigeminal schwannoma: tumor control and functional preservation Clinical article. $\mathrm{J}$ Neurosurg 110:553-558. https://doi.org/10.3171/2008.7.jns0812

19. Kida Y, Kobayashi T, Tanaka T (1998) Radiosurgery of trigeminal neurinoma. In: Kondziolka D (ed) Radiosurgery, vol 2. Karger, Basel, pp 8-15

20. Kondziolka D, Lunsford LD, McLaughlin MR, Flickinger JC (1998) Long-term outcomes after radiosurgery for acoustic neuromas. N Engl J Med 339:1426-1433. https://doi.org/10.1056/ NEJM199811123392003

21. Kondziolka D, Zorro O, Lobato-Polo J, Kano H, Flannery TJ, Flickinger JC, Lunsford LD (2010) Gamma Knife stereotactic radiosurgery for idiopathic trigeminal neuralgia. J Neurosurg 112: 758-765. https://doi.org/10.3171/2009.7.JNS09694

22. Konovalov AN, Spallone A, Mukhamedjanov DJ, Tcherekajev VA, Makhmudov UB (1996) Trigeminal neurinomas. A series of 111 surgical cases from a single institution. Acta Neurochir (Wien) 138:1027-1035. https://doi.org/10.1007/bf01412304

23. Mabanta SR, Buatti JM, Friedman WA, Meeks SL, Mendenhall WM, Bova FJ (1999) Linear accelerator radiosurgery for nonacoustic schwannomas. Int J Radiat Oncol Biol Phys 43:545548. https://doi.org/10.1016/s0360-3016(98)00445-3

24. Mathieu D, Kondziolka D, Flickinger JC, Niranjan A, Williamson R, Martin JJ, Lunsford LD (2007) Stereotactic radiosurgery for vestibular schwannomas in patients with neurofibromatosis type 2: an analysis of tumor control, complications, and hearing preservation rates. Neurosurgery 60:460-468; discussion 468-470. https://doi.org/10.1227/01.NEU.0000255340.26027.53

25. McCormick PC, Bello JA, Post KD (1988) Trigeminal schwannoma. Surgical series of 14 cases with review of the literature. J Neurosurg 69:850-860. https://doi.org/10.3171/jns.1988. 69.6.0850

26. Moher D, Liberati A, Tetzlaff J, Altman DG, Group P (2009) Reprint-preferred reporting items for systematic reviews and meta-analyses: the PRISMA statement. Phys Ther 89:873-880

27. Nettel B, Niranjan A, Martin JJ, Koebbe CJ, Kondziolka D, Flickinger JC, Lunsford LD (2004) Gamma knife radiosurgery for trigeminal schwannomas. Surg Neurol 62:435-444; discussion 444-436. https://doi.org/10.1016/j.surneu.2004.02.035

28. Pan L, Wang EM, Zhang N, Zhou LF, Wang BJ, Dong YF, Dai JZ, Cai PW (2005) Long-term results of Leksell gamma knife surgery for trigeminal schwannomas. J Neurosurg 102(Suppl):220-224. https://doi.org/10.3171/jns.2005.102.s_supplement.0220

29. Peciu-Florianu I, Tuleasca C, Comps JN, Schiappacasse L, Zeverino M, Daniel RT, Levivier M (2017) Radiosurgery in trochlear and abducens nerve schwannomas: case series and systematic review. Acta Neurochir 159:2409-2418. https://doi.org/10.1007/ s00701-017-3348-0

30. Peker S, Bayrakli F, Kilic T, Pamir MN (2007) Gamma-knife radiosurgery in the treatment of trigeminal schwannomas. Acta Neurochir (Wien) 149:1133-1137; discussion 1137. https://doi. org/10.1007/s00701-007-1285-9

31. Phi JH, Paek SH, Chung HT, Jeong SS, Park CK, Jung HW, Kim DG (2007) Gamma Knife surgery and trigeminal schwannoma: is it possible to preserve cranial nerve function? J Neurosurg 107:727732. https://doi.org/10.3171/JNS-07/10/0727

32. Pollock BE, Foote RL, Stafford SL (2002) Stereotactic radiosurgery: the preferred management for patients with nonvestibular schwannomas? Int J Radiat Oncol Biol Phys 52:1002-1007. https://doi.org/10.1016/s0360-3016(01)02711-0

33. Pollock BE, Link MJ, Leavitt JA, Stafford SL (2014) Dose-volume analysis of radiation-induced optic neuropathy after single-fraction stereotactic radiosurgery. Neurosurgery 75:456-460; discussion 460. https://doi.org/10.1227/NEU.0000000000000457

34. Regis J, Pellet W, Delsanti C, Dufour H, Roche PH, Thomassin JM, Zanaret M, Peragut JC (2002) Functional outcome after gamma knife surgery or microsurgery for vestibular schwannomas. J Neurosurg 97:1091-1100. https://doi.org/10.3171/jns.2002.97.5. 1091

35. Rigamonti D, Spetzler RF, Shetter A, Drayer BP (1987) Magnetic resonance imaging and trigeminal schwannoma. Surg Neurol 28: 67-70. https://doi.org/10.1016/0090-3019(87)90209-6

36. Rogers CL, Shetter AG, Fiedler JA, Smith KA, Han PP, Speiser BL (2000) Gamma knife radiosurgery for trigeminal neuralgia: the initial experience of The Barrow Neurological Institute. Int J Radiat Oncol Biol Phys 47:1013-1019

37. Ryu J, Lee SH, Choi SK, Lim YJ (2018) Gamma knife radiosurgery for trigeminal schwannoma: a 20-year experience with long-term treatment outcome. J Neurooncol 140:89-97. https://doi.org/10. 1007/s11060-018-2934-1

38. Samii M, Migliori MM, Tatagiba M, Babu R (1995) Surgical treatment of trigeminal schwannomas. J Neurosurg 82:711-718. https:// doi.org/10.3171/jns.1995.82.5.0711

39. Schisano G, Olivecrona H (1960) Neurinomas of the Gasserian ganglion and trigeminal root. J Neurosurg 17:306-322. https:// doi.org/10.3171/jns.1960.17.2.0306

40. Sheehan J, Yen CP, Arkha Y, Schlesinger D, Steiner L (2007) Gamma knife surgery for trigeminal schwannoma. J Neurosurg 106:839-845. https://doi.org/10.3171/jns.2007.106.5.839

41. Snyder MH, Shepard MJ, Chen CJ, Sheehan JP (2018) Stereotactic radiosurgery for trigeminal schwannomas: a 28-year single-center experience and review of the literature. World Neurosurg 119: e874-e881. https://doi.org/10.1016/j.wneu.2018.07.289

42. Sun J, Zhang J, Yu X, Qi S, Du Y, Ni W, Hu Y, Tian Z (2013) Stereotactic radiosurgery for trigeminal schwannoma: a clinical retrospective study in 52 cases. Stereotact Funct Neurosurg 91:236 242. https://doi.org/10.1159/000345258

43. Sun S, Liu A, Wang C, Luo B, Wang M (2006) Clinical analysis of Gamma Knife surgery for trigeminal schwannomas. J Neurosurg 105(Suppl):144-148. https://doi.org/10.3171/sup.2006.105.7.144

44. Tsao MN, Sahgal A, Xu W, De Salles A, Hayashi M, Levivier M, Ma L, Martinez R, Regis J, Ryu S, Slotman BJ, Paddick I (2017) Stereotactic radiosurgery for vestibular schwannoma: International Stereotactic Radiosurgery Society (ISRS) Practice Guideline. J Radiosurg SBRT 5:5-24

45. Tuleasca C, George M, Faouzi M, Schiappacasse L, Leroy HA, Zeverino M, Daniel RT, Maire R, Levivier M (2016) Acute clinical adverse radiation effects after Gamma Knife surgery for vestibular schwannomas. J Neurosurg 125:73-82. https://doi.org/10.3171/ 2016.7.GKS161496

46. van de Langenberg R, Hanssens PE, van Overbeeke JJ, Verheul JB, Nelemans PJ, de Bondt BJ, Stokroos RJ (2011) Management of large vestibular schwannoma. Part I. Planned subtotal resection followed by Gamma Knife surgery: radiological and clinical aspects. J Neurosurg 115:875-884. https://doi.org/10.3171/2011.6. JNS101958

47. Wallner KE, Pitts LH, Davis RL, Sheline GE (1988) Radiation therapy for the treatment of non-eight nerve intracranial neurilemmoma. Int J Radiat Oncol Biol Phys 14:287-290. https:// doi.org/10.1016/0360-3016(88)90434-8 
48. Wolf A, Naylor K, Tam M, Habibi A, Novotny J, Liscak R, Martinez-Moreno N, Martinez-Alvarez R, Sisterson N, Golfinos JG, Silverman J, Kano H, Sheehan J, Lunsford LD, Kondziolka D (2019) Risk of radiation-associated intracranial malignancy after stereotactic radiosurgery: a retrospective, multicentre, cohort study. Lancet Oncol 20:159-164. https://doi.org/10.1016/S14702045(18)30659-4

49. Yamasaki T, Nagao S, Kagawa T, Takamura M, Moritake K, Tanaka Y, Kida T, Kobayashi T (1996) Therapeutic effectiveness of combined microsurgery and radiosurgery in a patient with a huge trigeminal neurinoma. No To Shinkei 48:845-850

50. Yianni J, Dinca EB, Rowe J, Radatz M, Kemeny AA (2012) Stereotactic radiosurgery for trigeminal schwannomas. Acta
Neurochir (Wien) 154:277-283. https://doi.org/10.1007/s00701011-1146-7

51. Zabel A, Debus J, Thilmann C, Schlegel W, Wannenmacher M (2001) Management of benign cranial nonacoustic schwannomas by fractionated stereotactic radiotherapy. Int J Cancer 96:356-362. https://doi.org/10.1002/ijc.1036

52. Zakrzewska JM, Linskey ME (2014) Trigeminal neuralgia. BMJ 348:g474. https://doi.org/10.1136/bmj.g474

Publisher's note Springer Nature remains neutral with regard to jurisdictional claims in published maps and institutional affiliations. 